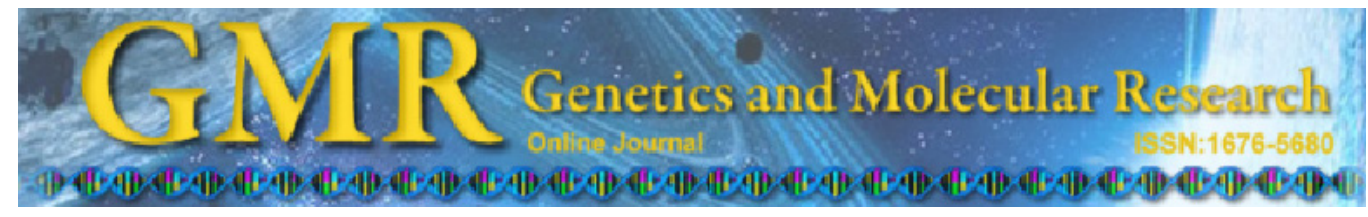

\title{
Distribution of HLA-B27 and CYP2D6*4 mutations in the middle Black Sea area (Tokat) of Turkey
}

\author{
S. Sahin, L. Aydogan, I. Benli and H. Ozyurt \\ Department of Biochemistry, Faculty of Medicine, \\ Gaziosmanpasa University, Tokat, Turkey \\ Corresponding author: S. Sahin \\ E-mail: semsettinsahin@hotmail.com
}

Genet. Mol. Res. 10 (4): 3987-3991 (2011)

Received August 10, 2011

Accepted November 17, 2011

Published December 2, 2011

DOI http://dx.doi.org/10.4238/2011.December.2.3

\begin{abstract}
We analyzed distribution of HLA-B27 and CYP2D6*4 mutations in 249 patients from Tokat province in Turkey with symptoms of arthritis, sacroiliac, joint and back pain, using a LightCycler 480 II Real-Time PCR thermal cycler. The Genes-4U was applied for studying HLA-B27 mutation, and the Tib-Molbiol commercial kit was used to examine the CYP2D6*4 mutation. Among the 249 patients, $18.5 \%$ had the HLA-B27 mutation. The CYP2D6*4 mutation was found in $22.0 \%$ (six homozygotes). Ten patients had both mutations. These frequencies are similar to what has been reported from other populations.
\end{abstract}

Key words: HLA-B27; CYP2D6*4; Mutation; Real-time PCR 


\section{INTRODUCTION}

The HLA (human leukocyte antigen) region is the most polymorphic region as defined in IMGT/HLA. This region located in the short arm of chromosome 6 within MHC (major histocompatibility complex) has been extensively studied because of its critical role in organ and stem cell transplantation (Buhler and Sanchez-Mazas, 2011).

The HLA-B27 family contains a great number and subtypes of allele variations whose heterogeneity was previously determined and whose ethnic distribution differs (Khan, 2010). According to a study in which there were HLA-B27 positive children, JIA (juvenile idiopathic arthritis) was related to 8 HLA-B27 allele types $(* 2702, * 2703, * 2704, * 2705$, $* 2710, * 2715, * 2717, * 2728)$. Of these, the most common alleles are HLA B*2705, $* 2710$ and $* 2717$ (Stanevicha et al., 2010).

Unlike many complex genetic diseases, a single gene (HLA-B) plays an important role in ankylosing spondylitis (AS). B27 allele contributes up to $40 \%$ of all genetic load and is the major factor for many other spondyloarthropathies (SpA) (Reveille, 2006; Brown, 2006). It has been clearly stated that the powerful relation between MHC and AS is HLA-B27 (Thomas and Brown, 2010). In SpA patients, just like in 95\% of AS patients carrying B27, HLA-B27

is observed at a high frequency. For this reason, SpA appears as one of the best examples of the diseases related to the HLA marker. Human and transgenic animal model link and relation studies have proven the role of B27 in AS (Taurog, 2009; Thomas and Brown, 2010).

Genetic polymorphisms of drug-metabolizing enzymes show the source of individual variants in treatment response. Among these enzymes, CYP2D6 and CYP2C19 play an important role (Zanger et al., 2008). CYP2D6 is a component of one the major metabolic pathways for central nerve system drugs, many of which are depressants, such as antidepressants, antipsychotics, opioids and antihistamines (Ingelman-Sundberg et al., 2007).

Up to now, more than 50 human CYP isoenzymes have been determined (Ma et al., 2002). Of these, more than 20, including CYP2A6, CYP2C9, CYP2C19 and CYP2D6, are functionally polymorphic. Therefore, about $40 \%$ of CYP linked to drug metabolism involve polymorphic enzymes (Ingelman-Sundberg, 2005). At least, 15 allele variations of CYP2D6 can cause weak-metabolizing phenotypes, but $75 \%$ of weak-metabolizing phenotypes are homozygous CYP2D6*4 (Brown et al., 2000). CYP2D6*4 (allele frequency of 20\%) was found to be the most common variant in Caucasians (Bradford, 2002).

\section{MATERIAL AND METHODS}

In this study, 249 patients from the Middle Black Sea area of Turkey were included, who were seen at Gaziosmanpasa University Health Search and Application Center. The complaints of the patients were arthritis, sacroiliac and joint pains and backaches. HLA-B27 and CYP2D6*4 mutations were studied in these patients. The purpose was explained to them and their written permission was obtained using a "Patient Enlightened Approval Form". A venous blood sample $(2 \mathrm{~mL})$ was drawn for routine analysis and placed in tubes containing EDTA. DNA isolation was done from whole blood using the Roche High Pure PCR Template Preparation Kit. HLA-B27 and CYP2D6*4 mutation screening was performed based with the real-time PCR method using a LightCycler 480 II Real-Time PCR thermal cycler.

Using the real-time polymerase chain reaction (RT-PCR) method, the increase in the 
fluorescence of the product obtained by the amplification of DNA was followed in real time. Gene polymorphism was determined by analyzing the detailed melting curve of the PCR product obtained. The Genes-4U kit was used for the HLA-B27 mutations and the Tib-Molbiol kit for the CYP2D6*4 mutations.

\section{RESULTS}

HLA-B27 and CYP2D6*4 mutations were studied in 249 patients. Based on the results, HLA-B27 mutation was positive in $46(18.47 \%)$ patients. CYP2D6*4 mutation was heterozygous in $49(19.67 \%)$ patients and homozygous in 6 samples $(2.4 \%)$. Ten patients $(4.01 \%)$ were found carrying both HLA-B27 and CYP2D6*4 mutations. There were $158(63.45 \%)$ patients with no mutations. Results are given in detail in Table 1.

Table 1. Patient number surveyed for HLA-B27 and CYP2D6*4 mutations and ratios.

\begin{tabular}{lccc}
\hline Mutation name & Mutation number/ratio $(\mathrm{N}=249)$ & & \\
\hline HLA-B27 & Wild type & Positive \\
& $203(81.52 \%)$ & $46(18.47 \%)$ & \\
\hline CYP2D6*4 & Wild type & Heterozygote & Homozygote \\
& $194(77.91 \%)$ & $49(19.67 \%)$ & $6(2.40 \%)$ \\
\hline
\end{tabular}

\section{DISCUSSION}

Each of the HLA-B27 positive patients could have had a different illness (enthesitis, polyarthritis, oligoarthritis, arthritis, ankylosing spondylitis) in addition to a different level of illness activity (Stanevicha et al., 2010). HLA-B27 is related to SpA which are a group of inflammatory diseases affecting many areas such as skin, ankle and tarsal joints (Breban et al., 2004).

As a multi-systemic disease characterized by ankylosis of intervertebral, costovertebral and sacroiliac joints, AS shows genetic familial transition, and $95 \%$ of AS patients are HLA-B27 positive. Twenty percent of people with HLA-B27 have AS disease (Olivieri et al., 1998; Edwards et al., 2000).

In normal individuals, the HLA-B27 rate was found to be 8-14\% (Arnett, 1997; Taurog and Lipsky, 1998). In people with HLA-B27 and HLA Bw60 combination, risk of ankylosing spondylitis triples. Incidents were reported as 7.3 in 100,000 people (Van der Linden et al., 2005).

The frequency of HLA-B27 has been shown to vary in different ethnic groups. HLAB27 prevalence was found to be $18-50 \%$ in American Indians, $10-16 \%$ in Scandinavians, 6-9\% in Western Europe, 2-6\% in Southern Europe, 6-8\% in Pakistanis, 2-6\% in Indians, 1\% in Japanese, and 1\% in Africans (Van der Unden, 1997). This rate varies between 4 and 13\% in Caucasian Americans. The rate is 2-3\% in African Americans (Khan, 1995; Tay-Kearney et al., 1996). While $95 \%$ of AS patient carry HLA-B27, in the general population this rate is $10 \%$ in Europeans, $1 \%$ in Japanese and $10-50 \%$ in American Indians, which is the highest number (Brewerton et al., 1973; Ball and Khan, 2001). In a study conducted in Turkey, HLAB27 phenotype frequency in a healthy Turkish population was reported to be $6.8 \%$ (Gul et al., 
2002). In a study carried out by Gunal et al. (2008) in 112 Turkish AS patients, HLA-B27 was positive in $79(70 \%)$ patients. In our study, the number of patients HLA-B27 positive was 46 $(18.47 \%)$ out of 249 . This number was higher compared to the results reported by Gul et al. (2002) and was lower than the results reported by Gunal et al. (2008). This comparison suggests that patients with complaints of various aches including AS may have a high chance of being positive for HLA-B27.

HLA-B27 and CYP2D6*4 are susceptibility alleles for AS. CYP2D6*4 homozygous patients have a higher risk for AS. This type of high risk was not observed in heterozygotes (Beyeler et al., 1996; Brown et al., 2000). In addition, susceptibility for AS is an important factor for the cure of AS patients (Wagner et al., 1998; Brown et al., 2000).

According to Brown et al. (2002), the fact that there was no relation between observed heterozygote CYP2D6*4 and AS suggests either a direct relationship with polymorphism playing a recessive role or there was a strong connection inequality with the allele playing a recessive role.

While CYP2D6*4 is a predominant defective allele in the Caucasian population, it is rare in the Asian population (1-3\%) (Gjerde et al., 2008). In a study conducted in Turkey, CYP2D6*4 homozygote mutation rate was $4 \%$ and allele frequency was 0.21 (Koseler et al., 2007). Aydın et al. (2005) found that CYP2D6*4 allele frequency in Turkey was $15.4 \%$. The results of allele frequency and homozygote prevalence of CYP2D6*4 mutation in Turkey are given in Table 2. Allele frequencies in various populations are the following: $21 \%$ in Germans, $18 \%$ in Americans, $1 \%$ in Japanese and $8 \%$ in African Americans (Aydın et al., 2005). In our study, the number of patients with CYP2D6*4 mutation was 55 (22.07\%): 49 (19.67\%) were heterozygous and $6(2.4 \%)$ were homozygous. In all patients, CYP2D6*4 allele frequency was 0.122 . When we compared the results of our study with those of Aynacioglu et al. (1999) in which there were 404 patients, and of Aydin et al. (2005) in which there were 140 patients, we observed that allele frequencies and homozygous mutations were close.

Table 2. CYP2D6*4 allele frequency and homozygote prevalence in various studies.

\begin{tabular}{lcc}
\hline & CYP2D6*4 allele frequency & CYP2D6*4 homozygote prevalence (\%) \\
\hline Aynacioglu et al., $1999(\mathrm{~N}=404)$ & 0.11 & 1.5 \\
Bozkurt et al. $(\mathrm{N}=326)$ & - & 3.4 \\
Aydin et al., 2005 $(\mathrm{N}=140)$ & 0.154 & 2.4 \\
Koseler et al., 2007 $(\mathrm{N}=100)$ & 0.21 & 4.0 \\
Our study $(\mathrm{N}=249)$ & 0.12 & 2.4 \\
\hline
\end{tabular}

We found that although there are various cultural structures in the Middle Black Sea area of Turkey, the distribution of HLA-B27 and CYP2D6*4 mutations was similar to that in other parts of the country.

\section{REFERENCES}

Arnett FC (1997). Ankylosing Spondylitis. In: Arthritis and Allied Conditions. A Textbook of Rheumatology (Koopman WJ, ed.). Williams and Wilkins, Baltimore, 1197-1208.

Aydin M, Hatirnaz O, Erensoy N and Ozbek U (2005). CYP2D6 and CYP1A1 mutations in the Turkish population. Cell Biochem. Funct. 23: 133-135.

Aynacioglu AS, Sachse C, Bozkurt A, Kortunay S, et al. (1999). Low frequency of defective alleles of cytochrome P450 
enzymes 2C19 and 2D6 in the Turkish population. Clin. Pharmacol. Ther. 66: 185-192.

Ball EJ and Khan MA (2001). HLA-B27 polymorphism. Joint Bone Spine 68: 378-382.

Beyeler C, Armstrong M, Bird HA, Idle JR, et al. (1996). Relationship between genotype for the cytochrome P450 CYP2D6 and susceptibility to ankylosing spondylitis and rheumatoid arthritis. Ann. Rheum. Dis. 55: 66-68.

Bradford LD (2002). CYP2D6 allele frequency in European Caucasians, Asians, Africans and their descendants. Pharmacogenomics 3: 229-243.

Breban M, Hacquard-Bouder C and Falgarone G (2004). Animal models of HLA-B27-associated diseases. Curr. Mol. Med. 4: 31-40.

Brewerton DA, Hart FD, Nicholls A, Caffrey M, et al. (1973). Ankylosing spondylitis and HL-A 27. Lancet 1: 904-907.

Brown MA (2006). Non-major-histocompatibility-complex genetics of ankylosing spondylitis. Best Pract. Res. Clin. Rheumatol. 20: 611-621.

Brown MA, Edwards S, Hoyle E, Campbell S, et al. (2000). Polymorphisms of the CYP2D6 gene increase susceptibility to ankylosing spondylitis. Hum. Mol. Genet. 9: 1563-1566.

Buhler S and Sanchez-Mazas A (2011). HLA DNA sequence variation among human populations: molecular signatures of demographic and selective events. PLoS One 6: e14643.

Edwards JC, Bowness P and Archer JR (2000). Jekyll and Hyde: the transformation of HLA-B27. Immunol. Today 21: 256-260.

Gjerde J, Hauglid M, Breilid H, Lundgren S, et al. (2008). Effects of CYP2D6 and SULT1A1 genotypes including SULT1A1 gene copy number on tamoxifen metabolism. Ann. Oncol. 19: 56-61.

Gul A, Uyar FA, Inanc M, Ocal L, et al. (2002). A weak association of HLA-B*2702 with Behcet's disease. Genes Immun. 3: 368-372.

Gunal EK, Sarvan FO, Kamali S, Gul A, et al. (2008). Low frequency of HLA-B27 in ankylosing spondylitis patients from Turkey. Joint Bone Spine 75: 299-302.

Ingelman-Sundberg M (2005). Genetic polymorphisms of cytochrome P450 2D6 (CYP2D6): clinical consequences, evolutionary aspects and functional diversity. Pharmacogenomics J. 5: 6-13.

Ingelman-Sundberg M, Sim SC, Gomez A and Rodriguez-Antona C (2007). Influence of cytochrome P450 polymorphisms on drug therapies: pharmacogenetic, pharmacoepigenetic and clinical aspects. Pharmacol. Ther. 116: 496-526.

Khan MA (1995). HLA-B27 and its subtypes in world populations. Curr. Opin. Rheumatol. 7: 263-269.

Khan MA (2010). Remarkable polymorphism of HLA-B27: an ongoing saga. Curr. Rheumatol. Rep. 12: 337-341.

Koseler A, Ilcol YO and Ulus IH (2007). Frequency of mutated allele CYP2D6*4 in the Turkish population. Pharmacology 79: 203-206.

Ma MK, Woo MH and McLeod HL (2002). Genetic basis of drug metabolism. Am. J. Health Syst. Pharm. 59: 2061-2069.

Olivieri I, Barozzi L, Padula A, De Matteis M, et al. (1998). Clinical manifestations of seronegative spondylarthropathies. Eur. J. Radiol. 27 (Suppl 1): S3-S6.

Reveille JD (2006). Major histocompatibility genes and ankylosing spondylitis. Best Pract. Res. Clin. Rheumatol. 20: 601-609.

Stanevicha V, Eglite J, Zavadska D, Sochnevs A, et al. (2010). HLA B27 allele types in homogeneous groups of juvenile idiopathic arthritis patients in Latvia. Pediatr. Rheumatol. Online J. 8: 26.

Taurog JD (1997). Seronegative Spondyloarthropathies. Epidemiology, Pathology and Pathogenesis. In: Primeron the Rheumatic Disease (Klippel JH, ed.). Arthritis Foundation, Atlanta, 180-183.

Taurog JD (2009). Animal models of spondyloarthritis. Adv. Exp. Med. Biol. 649: 245-254.

Taurog JD and Lipsky PE (1998). Ankylosing Spondylitis, Reactive Arthritis, and Undifferentiated Spondyloarthropathy. In: Harrison's Principles of Internal Medicine (Fauci AS, Isselbacher KJ, Braunwald E, Wilson JD, et al., eds.). McGraw-Hill Press, New York, 1904-1906.

Tay-Kearney ML, Schwam BL, Lowder C, Dunn JP, et al. (1996). Clinical features and associated systemic diseases of HLA-B27 uveitis. Am. J. Ophthalmol. 121: 47-56.

Thomas GP and Brown MA (2010). Genetics and genomics of ankylosing spondylitis. Immunol. Rev. 233: 162-180.

Van der Linden S, Van der Heijde D and Braun J (2005). Ankylosing Spondilitis. In: Kelley's Textbook of Rheumatology (Haris ED, Budd RC, Firestein GS, Genovese MC, et al., eds.). 7th edn. Elsevier Saunders, Philadelphia, 1125-1141.

Van der Unden (1997). Ankylosing Spondylitis. In: Texbook of Rheumatology (Kelley WN, Harris ED, Ruddy S and Sledge CB, eds.). W.B. Saunders Company, Philadelphia, 969-982.

Wagner T, Oberkanins C, Weinmayr B, Helmberg W, et al. (1998). HLA-B*27 typing by group-specific hybridization in microtiter plates. Tissue Antigens 52: 175-178.

Zanger UM, Turpeinen M, Klein K and Schwab M (2008). Functional pharmacogenetics/genomics of human cytochromes P450 involved in drug biotransformation. Anal. Bioanal. Chem. 392: 1093-1108. 